\title{
Lipophilic profile of the edible halophyte Salicornia ramosissima
}

\author{
Vera M.S. Isca ${ }^{a}$, Ana M.L. Seca ${ }^{a, b}$, Diana C.G.A. Pinto ${ }^{a, *}$, Helena Silva $^{c}$, Artur M.S. Silva $^{\text {a }}$ \\ ${ }^{a}$ Department of Chemistry \& QOPNA, University of Aveiro, Campus de Santiago, 3810-193 Aveiro, Portugal \\ ${ }^{\mathrm{b}}$ DCTD, University of Azores, Rua Mãe de Deus, 9501-801 Ponta Delgada, Portugal \\ ${ }^{\mathrm{c}}$ Department of Biology \& CESAM, University of Aveiro, 3810-193 Aveiro, Portugal
}

\section{A R T I C L E I N F O}

\section{Article history:}

Received 26 February 2014

Received in revised form 19 May 2014

Accepted 20 May 2014

Available online 2 June 2014

\section{Keywords:}

Salicornia ramosissima

Lipophilic profile

Fatty acids

PUFAs

Sterols

\begin{abstract}
A B S T R A C T
Salicornia ramosissima J. Woods is considered, in the Iberian Peninsula and France, a gourmet product. Nevertheless, is one of the less studied Salicornia species. In this work, GC-MS was employed to, for the first time; fully characterise the lipophilic profile of S. ramosissima and to assess the effect of natural and extra irrigation in that profile. The obtained data showed esterified and free fatty acids, fatty alcohol, sterols, alkanes and aromatic acid derivatives, being palmitic acid, tetracosanol and octacosanol the most abundant compounds. The extra irrigation increases significantly $(P<0.001)$ the content of esterified lipophilic compounds. Stigmastanol, 24-ethyl- $\delta(22)$-coprostenol, several secondary fatty alcohols and dicarboxylic acids were identified for the first time in Salicornia genus. Several of the detected compounds are known to have health benefits and our results suggest that $S$. ramosissima should be considered as an important dietary source of lipophilic phytochemicals.
\end{abstract}

(c) 2014 Elsevier Ltd. All rights reserved.

\section{Introduction}

Salicornia ramosissima J. Woods (Chenopodiaceae), is an annual hygrohalophytic pioneer, included in the species aggregate S. europaea agg., widely distributed in the salt marshes and salt pans of Ria de Aveiro (Portugal) and also present in many salt marshes of the Iberian Peninsula (Castroviejo, 1990; Silva, Caldeira, \& Freitas, 2007), Western France (Jefferies \& Gottlieg, 1982) and in Serbia (Milić et al., 2011). It has articulated and succulent stems apparently leafless (Davy, Bishop, \& Costa, 2001) and whose optimal growth is at low salinity, although tolerates high salinity levels (Silva et al., 2007). Salicornia genus is also well known for its applications as additive in the production of glass and soap (Davy et al., 2001), as medicinal herbs (Isca, Seca, Pinto, \& Silva, 2014) [for example S. herbacea is widespread used in Korea folk medicine for the treatment of constipation, diabetes, intestinal ailment, nephropathy, cancer, asthma, arthritis and hepatitis (Rhee, Park, \& Cho, 2009)] and also in some applications in human and domestic animals diet (Jang, Kim, Choi, Woo, \& Choi, 2007). S. ramosissima is known in England as "purple glasswort" and in Portugal and Spain as "erva-salada" where is considered a gourmet product for human consumption. For example, the fresh branch tips are consumed in fresh salads and, due to its salt content, is

\footnotetext{
* Corresponding author. Tel.: +351 234401 407; fax: +351234370 084.

E-mail addresses: veraisca@ua.pt (V.M.S. Isca), anaseca@uac.pt (A.M.L. Seca), diana@ua.pt (D.C.G.A. Pinto), hsilva@ua.pt (H. Silva), artur.silva@ua.pt (A.M.S. Silva).
}

used in dry and milled form as cooking salt substitute (named green salt).

In view of the cardinal role of dietary fats in human health and disease, the analysis of lipophilic content and, particularly, the fatty acid composition has become a research priority on lipid chemistry and nutritional characterisation of Salicornia species. In fact, the fatty acid profile of S. bigelovii, S. europaea and their hybrid variety seeds oils are characterised by a high degree of unsaturated acids, mainly $\alpha$-linolenic and linoleic acids (Guil, Torija, Giménez, \& Rodríguez, 1996; Lu, Zhang, Wang, Cai, Zhou \& Zhu, 2010; Isca et al., 2014). S. ramosissima is one of the least studied species and in our literature survey we just found one work where the authors examined the cell walls and reported the identification of ferulic and acetic acids, monosaccharides, galacturonic acid and proteins (Renard, Champenois, \& Thibault, 1993). Therefore, considering the growing interest in the exploitation of spontaneous S. ramosissima as a foodstuff and the lack of detailed information on the lipophilic composition, as well as our interest in the search for new healthy plant and/or constituents, we examined the lipophilic profile of $S$. ramosissima. Herein we describe the detailed chemical characterisation of the lipophilic fractions from plants that growing in two different irrigation conditions by gas chromatography-mass spectrometry (GC-MS). Fifty seven compounds were identified from which eleven are reported for the first time in the Salicornia genus. This knowledge can open new perspectives for the valorisation of this species and promoting their economic development. 